\title{
Recombinant Production of MFHR1, A Novel Synthetic Multitarget Complement Inhibitor, in Moss Bioreactors
}

\section{OPEN ACCESS}

Edited by:

Anneli Marjut Ritala,

VTT Technical Research Centre of

Finland Ltd, Finland

Reviewed by:

Mareike Schallenberg-Rüdinger, Universität Bonn, Germany

Muriel Bardor,

Université de Rouen, France

${ }^{*}$ Correspondence:

Eva L. Decker

eva.decker@biologie.uni-freiburg.de orcid.org/0000-0002-9151-1361

torcid.org/0000-0003-2820-6505 torcid.org/0000-0002-5496-6711

‡These authors have contributed equally to this work

Specialty section:

This article was submitted to

Plant Biotechnology,

a section of the journal

Frontiers in Plant Science

Received: 28 November 2018

Accepted: 19 February 2019

Published: 20 March 2019

Citation:

Top O, Parsons J, Bohlender LL, Michelfelder S, Kopp P, Busch-Steenberg $C$, Hoernstein SNW, Zipfel PF, Häffner K,

Reski $R$ and Decker EL (2019) Recombinant Production of MFHR1,

A Novel Synthetic Multitarget

Complement Inhibitor, in Moss Bioreactors.

Front. Plant Sci. 10:260. doi: 10.3389/fp/s.2019.00260

\author{
Oguz Top ${ }^{1,2 \neq \neq}$, Juliana Parsons ${ }^{1 \neq}$, Lennard L. Bohlender ${ }^{1}$, Stefan Michelfelder ${ }^{3}$, \\ Phillipp Kopp ${ }^{1}$, Christian Busch-Steenberg', Sebastian N. W. Hoernstein', \\ Peter F. Zipfel ${ }^{4}$, Karsten Häffner ${ }^{3}$, Ralf Reski ${ }^{1,2,5 t}$ and Eva L. Decker ${ }^{1 *}$
}

${ }^{1}$ Department of Plant Biotechnology, Faculty of Biology, University of Freiburg, Freiburg, Germany, ${ }^{2}$ Spemann Graduate School of Biology and Medicine (SGBM), University of Freiburg, Freiburg, Germany, ${ }^{3}$ Faculty of Medicine, Department of General Pediatrics, Adolescent Medicine and Neonatology, Medical Center - University Freiburg, University of Freiburg, Freiburg, Germany, ${ }^{4}$ Leibniz Institute for Natural Product Research and Infection Biology, Friedrich Schiller University, Jena, Germany, ${ }^{5}$ Signalling Research Centres BIOSS and CIBSS, University of Freiburg, Freiburg, Germany

The human complement system is an important part of the immune system responsible for lysis and elimination of invading microorganisms and apoptotic body cells. Improper activation of the system due to deficiency, mutations, or autoantibodies of complement regulators, mainly factor $\mathrm{H}(\mathrm{FH})$ and $\mathrm{FH}$-related proteins (FHRs), causes severe kidney and eye diseases. However, there is no recombinant $\mathrm{FH}$ therapeutic available on the market. The first successful recombinant production of $\mathrm{FH}$ was accomplished with the moss bioreactor, Physcomitrella patens. Recently, a synthetic regulator, MFHR1, was designed to generate a multitarget complement inhibitor that combines the activities of $\mathrm{FH}$ and the FH-related protein 1 (FHR1). The potential of MFHR1 was demonstrated in a proof-of-concept study with transiently transfected insect cells. Here, we present the stable production of recombinant glyco-engineered MFHR1 in the moss bioreactor. The key features of this system are precise genome engineering via homologous recombination, Good Manufacturing Practice-compliant production in photobioreactors, high batch-tobatch reproducibility, and product stability. Several potential biopharmaceuticals are being produced in this system. In some cases, these are even biobetters, i.e., the recombinant proteins produced in moss have a superior quality compared to their counterparts from mammalian systems as for example moss-made aGal, which successfully passed phase I clinical trials. Via mass spectrometry-based analysis of moss-produced MFHR1, we now prove the correct synthesis and modification of this glycoprotein with predominantly complex-type N-glycan attachment. Moss-produced MFHR1 exhibits cofactor and decay acceleration activities comparable to $\mathrm{FH}$, and its mechanism of action on multiple levels within the alternative pathway of complement activation led to a strong inhibitory activity on the whole alternative pathway, which was higher than with the physiological regulator $\mathrm{FH}$.

Keywords: Physcomitrella patens, moss bioreactor, factor $\mathrm{H}$, plant-made recombinant pharmaceuticals, synthetic complement inhibitor, alternative pathway of complement activation, aHUS, C3 glomerulopathy 


\section{INTRODUCTION}

Biopharmaceutical production is a steadily growing field within the pharmaceutical market (International Federation of Pharmaceutical Manufacturers \& Associations IFPMA, 2017). Plant-based systems can offer advantages in sectors neglected by the mainstream bacterial or mammalian systems and their current business models (Stoger et al., 2014). Impressive recent examples for fully developed plant production processes comprise, e.g., Protalix, the carrot-cell-derived Taliglucerase alfa from a stable production process, as well as the transiently expressed ZMapp antibody cocktail to fight Ebola infections (Zimran et al., 2011; Lomonossoff and D'Aoust, 2016), the announcement of the clinical phase 3 start for the seasonal quadrivalent influenza vaccine produced in Nicotiana benthamiana ${ }^{1}$ and the successful completion of clinical phase 1 for recombinant alphagalactosidase A (moss-aGal) produced in Physcomitrella patens ${ }^{2}$.

The development of pharmaceuticals treating diseases, which are associated with malfunction of the human complement system, may be an attractive field for plant-based production. As part of the innate immune system, the complement system is a crucial defense line against invading microorganisms (Thurman and Holers, 2006). Furthermore, it is essential for tissue homeostasis by discriminating damaged or apoptotic host cells from healthy tissues and promoting their elimination (Janeway and Medzhitov, 2002; Zipfel and Skerka, 2009). The activity of more than 50 plasma proteins functioning in a cascade of enzymatic reactions, either in plasma (fluid-phase) or on cell surfaces, has to be tightly controlled by regulatory proteins. The malfunction of these complement regulators can lead to over-activation of the system with the consequence of severe diseases, especially of the kidney and eyes (Józsi and Zipfel, 2008).

The complement system can be activated by three different mechanisms, the classical, lectin, and alternative pathway. They merge at the level of $\mathrm{C} 3$ activation by generating variants of the so-called C3 convertase, an enzymatic complex able to cleave C3 molecules into the active forms C3b, an opsonin, and C3a, an anaphylatoxin (Figure 1A; Thurman and Holers, 2006). The alternative pathway of complement activation (AP) constitutively hydrolyzes $\mathrm{C} 3$ at low levels, generating $\mathrm{C} 3\left(\mathrm{H}_{2} \mathrm{O}\right)$, and subsequently $\mathrm{C} 3\left(\mathrm{H}_{2} \mathrm{O}\right) \mathrm{Bb}$, the fluid-phase $\mathrm{C} 3$ convertase. In the so-called amplification loop, the $\mathrm{C} 3$ convertase produces more $\mathrm{C} 3 \mathrm{~b}$ molecules, and additional $\mathrm{C} 3$ convertase $(\mathrm{C} 3 \mathrm{bBb})$ is formed (Zipfel and Skerka, 2009). This pathway can also be initiated by the presence of bacterial lipopolysaccharides (LPS) (Pangburn et al., 1980). The last step in the proximal part of the alternative pathway comprises the addition of another $\mathrm{C} 3 \mathrm{~b}$ molecule to the $\mathrm{C} 3$ convertase, thus forming the $\mathrm{C} 5$ convertase $(\mathrm{C} 3 \mathrm{bBbC} 3 \mathrm{~b})$. The terminal pathway, common to all three routes of complement activation, starts with the C5 convertase-catalyzed cleavage of $\mathrm{C} 5$ to $\mathrm{C} 5 \mathrm{a}$ and $\mathrm{C} 5 \mathrm{~b}$ and involves the non-enzymatic assembly of a complex of $\mathrm{C} 5 \mathrm{~b}$ with the plasma proteins $\mathrm{C} 6, \mathrm{C} 7, \mathrm{C} 8$, and $\mathrm{C} 9$. This complex, the membrane attack complex (MAC) or terminal complement complex (TCC),

${ }^{1}$ http://medicago.com

${ }^{2}$ https://www.greenovation.com creates a pore on cell membranes leading to the lysis of target cells (Figure 1A; Morgan et al., 2016).

As $\mathrm{C} 3 \mathrm{~b}$ binds to infectious microbes as well as adjacent host cells alike and marks them for lysis, host tissues have to be protected from damage with the help of complement regulatory proteins (De Córdoba and De Jorge, 2008). Factor H (FH) is the main regulator of the activation and amplification of the alternative pathway cascade. It is a single-chain plasma glycoprotein consisting of 20 globular short consensus repeat (SCR) domains (Zipfel et al., 1999) and is active in the fluid phase as well as on host cell surfaces. $\mathrm{FH}$ inhibits $\mathrm{C} 3$-convertase $(\mathrm{C} 3 \mathrm{bBb})$ formation by competing with $\mathrm{FB}$ for binding to $\mathrm{C} 3 \mathrm{~b}$ and promotes the irreversible dissociation of preformed $\mathrm{C} 3 \mathrm{bBb}$ (decay acceleration activity) (Hourcade et al., 1999). It also acts as a cofactor for the factor I (FI)-dependent inactivation of $\mathrm{C} 3 \mathrm{~b}$ in the fluid phase, the so-called cofactor activity of $\mathrm{FH}$. While these activities reside in the N-terminal SCRs 1-4 of FH (Kühn et al., 1995), the C-terminal SCRs 19-20 interact with cell surfaces via binding to polyanions, such as glycosaminoglycans (GAGs), thus protecting host cells from complement attack.

Factor $\mathrm{H}$ forms a small family with five related proteins (FHR1-5), also composed of SCR domains which share a high degree of sequence identity (Skerka et al., 2013). FHR1 regulates the terminal complement pathway by binding to C5, preventing its activation and inhibiting TCC assembly later in the cascade (Heinen et al., 2009). In addition, homo- or heterodimers of FHR1, FHR2, and FHR5 can compete with FH for binding to polyanions resulting in a decrease of $\mathrm{FH}$ levels with the consequence of local complement activation on host cell surfaces (Fritsche et al., 2010). Although the exact role of FHRs on complement regulation is not yet fully clarified, it is proposed that expression levels and ratios of the different $\mathrm{FH}$-family members are necessary for fine-tuning of complement regulation (Józsi and Zipfel, 2008; Goicoechea de Jorge et al., 2013; Skerka et al., 2013).

Mutations in FH, mainly in the carboxy-terminus of the protein can lead to an ineffective local regulation of the complement system on host cells causing damage of tissues, especially on endothelia, and lead to microangiopathic hemolytic anemia and acute renal failure known as atypical hemolytic uremic syndrome (aHUS) (Józsi et al., 2005). Autoantibodies against FH or FH deficiency or mutations may cause an over-activation of the complement cascade and uncontrolled cleavage of C3, followed by a depletion of plasma C3 and accumulation of C3-cleavage products on the glomerular basement membrane of the kidney. These depositions are typical in C3 glomerulopathies (C3G) and lead to renal failure (Pickering et al., 2002; Noris and Remuzzi, 2015). Age-related macular degeneration (AMD), the major cause of irreversible loss of central vision, especially in the elderly population, is also linked to genetic variants of complement components, among others FH (Fritsche et al., 2016; Geerlings et al., 2017).

Treatment options for complement-associated renal diseases are limited. FH-substitution via plasmapheresis was shown to restore normal complement activity in aHUS and C3G patients (Cataland and $\mathrm{Wu}, 2014$ ). The use of Eculizumab, a monoclonal antibody inhibiting C5 activation and one of the most expensive pharmaceuticals worldwide, has significantly improved the 


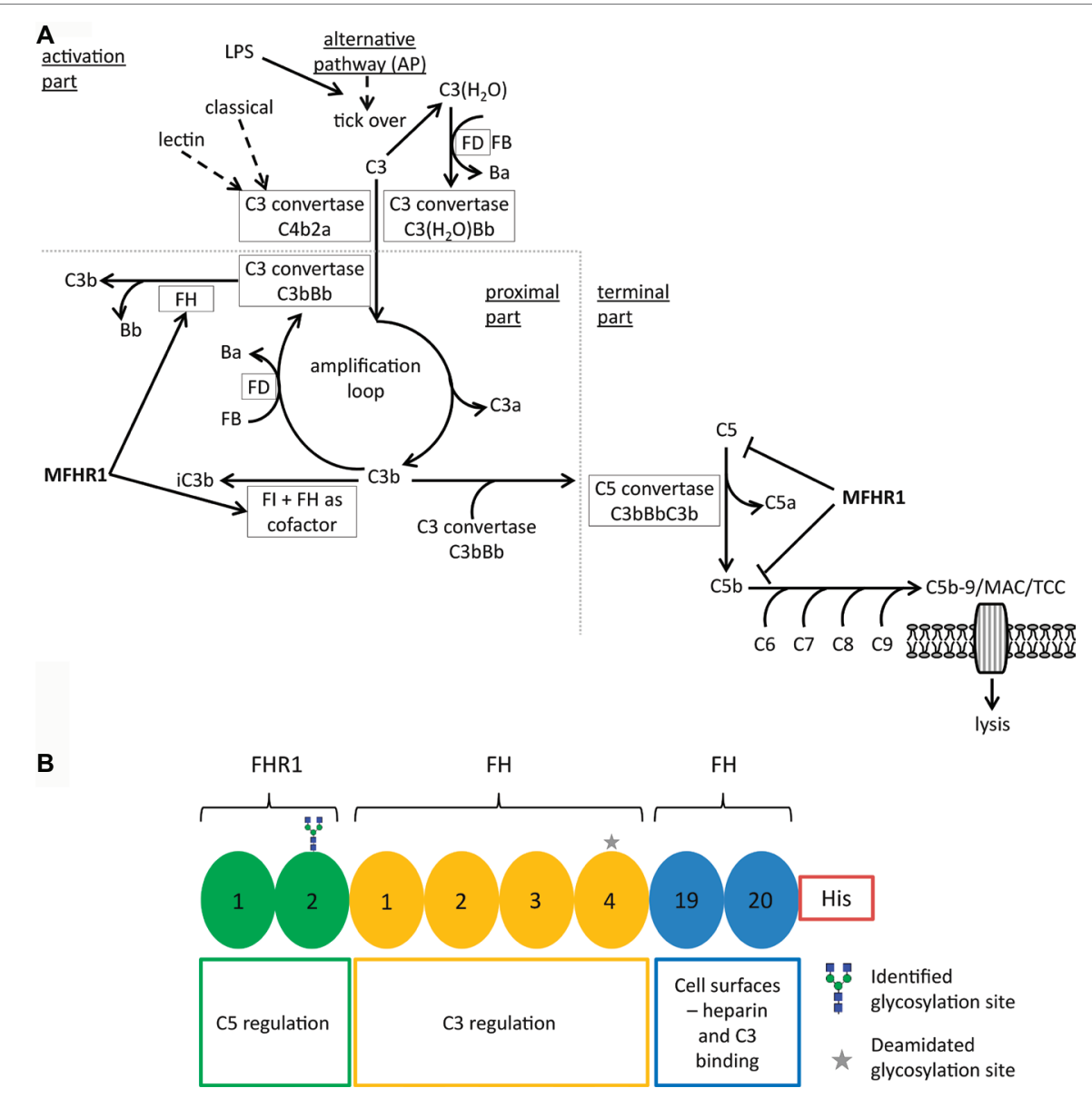

FIGURE 1 | Schematic representation of MFHR1 activity mechanism and structure. (A) MFHR1 regulates the alternative pathway simultaneously at different stages. Processes promoted by MFHR1 or activated by lipopolysaccharide (LPS) are marked by arrows and the step inhibited by MFHR1 is marked by a blocking arrow. F: complement regulatory factor, C: complement component, a or b: cleavage fragments, iC3b: inhibited C3b, AP: alternative pathway, LPS: lipopolysaccharide, MAC: membrane attack complex, TCC: terminal complement complex. (B) The synthetic MFHR1 protein comprises eight short consensus repeats (SCR), namely FHR1 $1_{1-2}, \mathrm{FH}_{1-4}$ and $\mathrm{FH}_{19-20}$, without artificial linkers and an $8 \mathrm{x}$ histidine tag at the $\mathrm{C}$-terminus (His).

clinical treatment of aHUS and $\mathrm{PNH}$ patients (Wong and Kavanagh, 2015). However, Eculizumab could not prevent the activation of C5 sufficiently for every patient (Harder et al., 2017). Moreover, Eculizumab is not effective in many patients suffering from C3G because it does not act on C3 level, thus does not prevent the accumulation of $\mathrm{C} 3$ cleavage products (Bomback et al., 2012). For these patients, the use of the physiological regulator $\mathrm{FH}$ will be beneficial, as it already acts on the level of $\mathrm{C} 3$ activation and inhibits over-activation of the system locally on host cells. In addition, the side effects of systemic inhibition treatment, e.g. a higher risk of infections (Fridkis-Hareli et al., 2011), will be avoided.

Recombinant $\mathrm{FH}$ was already successfully produced in $P$. patens. Moss-produced FH (mossFH) showed full in vitro complement regulatory activity, and it efficiently blocked AP activation and hemolysis induced by sera from aHUS patients (Büttner-Mainik et al., 2011; Michelfelder et al., 2017). Moreover, in a preclinical study, it decreased the pathological deposition of C3 cleavage products and increased the levels of plasma C3 in a murine C3G model (Michelfelder et al., 2017).
Recombinant proteins modulating the complement system on multiple levels of the activation cascade might be the key to the development of new therapeutics to treat complementrelated disorders. This strategy aims at the generation of smaller proteins with higher activity, implying that lower amounts of protein would be necessary to achieve the desired therapeutic effect. This is desirable, not only from the production point of view but also because of higher convenience for the patient. Recently, a novel synthetic multitarget regulator, MFHR1, was designed to combine the terminal pathway-regulating and dimerization domains of FHR1 with the functionally relevant C3-regulating and surface-binding domains of FH (Figure 1B; Michelfelder et al., 2018). After demonstrating the potential of MFHR1 as a biopharmaceutical in a proof-of-concept study using protein transiently expressed in insect cells, we now aimed to establish a stable production process for MFHR1 in the moss ( $P$. patens) bioreactor. The moss $P$. patens is an important model species in basic research as well as a biotechnology production platform with outstanding features including a fully sequenced genome, efficient homologous 
recombination-based genome-engineering, dominant haploid gametophytic stage in life cycle and Good Manufacturing Practice (GMP)-compliant production in moss photobioreactors (Rensing et al., 2008; Decker and Reski, 2012; Decker et al., 2014; Reski et al., 2015; Lang et al., 2018; Wiedemann et al., 2018). In the end of 2017, a milestone was reached when Greenovation Biotech $\mathrm{GmbH}$ successfully completed the phase I clinical study for the first moss-produced drug candidate, moss-aGal, against Fabry disease (Reski et al., 2018). Moreover, mossFH is currently being tested in preclinical trials and showed that it successfully reduced $\mathrm{C} 3$ deposits in a FH-deficient mouse model (Häffner et al., 2017; Michelfelder et al., 2017).

In this work, we report the successful stable production of the novel synthetic multitarget complement inhibitor MFHR1, a potentially promising pharmaceutical product, in the GMP-compliant production platform $P$. patens. Moss-produced MFHR1 was fully characterized by mass spectrometry. It retains the regulatory activity from both originating proteins, $\mathrm{FH}$ and FHR1, and displays a higher inhibitory activity in vitro on the whole alternative pathway than $\mathrm{FH}$, thus being a promising future biopharmaceutical product to cure complement-associated diseases.

\section{RESULTS}

\section{Transgenic Plant Generation}

For the production of MFHR1, the $\Delta x t / f t$ moss parental line was used, a double knockout for the $\alpha 1,3$ fucosyltransferase and the $\beta 1,2$ xylosyltransferase genes, which has been generated by gene targeting via homologous recombination and has been used previously for the production of FH (Michelfelder et al., 2017). This plant generates $\mathrm{N}$-glycans without $\alpha 1,3$-attached fucose or $\beta 1,2$-attached xylose (Koprivova et al., 2004; Huether et al., 2005; Michelfelder et al., 2017). MFHR1 expression was driven by the PpActin5 promoter (Weise et al., 2006) and targeting to the secretory pathway for its proper posttranslational modification was achieved by using the aspartic proteinase signal peptide of PpAP1 (Schaaf et al., 2004, 2005).

Plants surviving the selection procedure were directly screened by PCR for the presence of the transgene in the moss genome (Supplementary Figure 1) and via a sandwich ELISA for the production of MFHR1, from extracts of plant material grown on solid medium. Plants with a positive signal were transferred to liquid culture and screened again for productivity via ELISA (Supplementary Table 1). The two best-producing clones, P1 and P5, were selected for photobioreactor cultivation. Line P5 showed a slower biomass increase (Supplementary Figure 2). Therefore, according to its wild-type-like growth behavior and the overall level of MFHR1 production, P1 was chosen for further experiments.

\section{Establishment of a Production and Purification Process for mossMFHR1}

In order to accumulate biomass for the purification of MFHR1, the process in the photobioreactor was executed as a batch without harvesting material for 6 days (Figure 2A). From this time point onward, 2 L of suspension were harvested every day and replaced by fresh medium. The amount of biomass harvested in this 9-day process attained $190 \mathrm{~g}$ fresh weight $(\mathrm{FW})$, and the growth index was 53.4 (GI $=$ (biomass $_{\text {final }}-$ biomass $\left._{\text {initial }}\right) /$ biomass $\left._{\text {initial }}\right)$. Under these conditions, the concentration of MFHR1 in the plant material reached $100 \mu \mathrm{g}$ MFHR1/g FW and was constant until day 8, when it started to decrease (Figure 2B). Previous experiments have shown that the concentration of the protein of interest decreased further with the time of culture (Supplementary Figure 2). In the culture conditions used, the addition of $5 \mu \mathrm{M}$ naphthaleneacetic acid (NAA), a synthetic auxin, increased intracellular MFHR1 concentrations until the whole plant material was harvested 1 day later. All in all, more than $17 \mathrm{mg}$ MFHR1 accumulated in the $5 \mathrm{~L}$ bioreactor within 9 days.

His-tagged MFHR1 was extracted from 6- to 9-day-old plant material and purified via Ni-NTA chromatography. As measured via ELISA, the protein of interest eluted at an imidazole concentration above $250 \mathrm{mM}$, between fraction 6 and 16 (Supplementary Figure 3). Additionally, Coomassie staining and Western blotting confirmed the signal at the expected size of $58 \mathrm{kDa}$ (Figures 3A,B). Moreover, fractions 10-16 displayed suitable purity of the protein of interest (Figure 3A). A small amount of degraded protein was observed. The elution fractions 10-16 were collected, dialyzed against DPBS, concentrated via membrane ultrafiltration, and used for activity tests. Concentrated elution fractions 10-16 from homogenates of the parental plant $\Delta x t / f t$ were used as negative control for any activity of mossendogenous proteins. In both cases, fractions up to fraction 9 were discarded due to host-cell protein contamination as assessed by SDS-PAGE and Coomassie staining (Figure 3C). As MFHR1 is a novel fusion protein, a protein standard for quantification via ELISA had to be produced. After purification via Ni-NTA and ultrafiltration, the concentration of the protein of interest was assessed by band densitometry on Coomassie-stained gels, using BSA as a standard for protein amount (Figure 3C, E10-16). The concentration of mossMFHR1 used for activity assays relies on ELISA-quantifications using this standard.

\section{Structural Analyses Prove Correct Synthesis and Complex-Type N-Glycosylation of mossMFHR1}

Purified mossMFHR1 was identified with a sequence coverage of $91 \%$ by mass-spectrometric analysis (Figure 4). We can assume the correct cleavage of the signal peptide, as this peptide was not detected in the MS analysis, and the N-terminus of the mature protein could be confirmed. The carboxy-terminal His-tag remains undetected due to the low mass/charge ratio of this peptide, but nevertheless it is present, as MFHR1 was purified via Ni-NTA affinity chromatography. Furthermore, we analyzed the $\mathrm{N}$-glycosylation of mossMFHR1. As previously reported for both, human-derived and mossFH (Fenaille et al., 2007; Michelfelder et al., 2017), the putative glycosylation site NGS, originated from SCR4 of FH and located in SCR6 from MFHR1, was found to be deamidated to DGS, and therefore not glycosylated. Besides, the glycosylation site NIS located in 
A

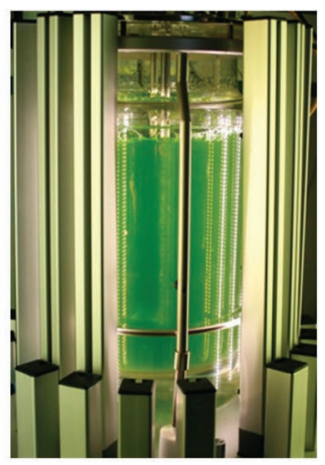

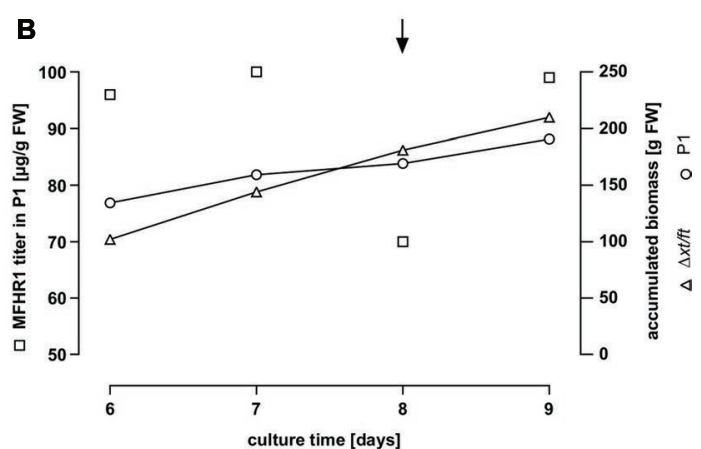

FIGURE 2 | MFHR1 production in the moss bioreactor. (A) Five liter photobioreactor setup of a Physcomitrella patens culture illuminated with LED lamps (in-house design). (B) Kinetics of MFHR1 concentration and biomass accumulation of the parental line $\Delta x t / f t$ and P1 in a culture carried out in the photobioreactor. The arrow marks the addition of $5 \mu \mathrm{M}$ NAA to the culture.

A

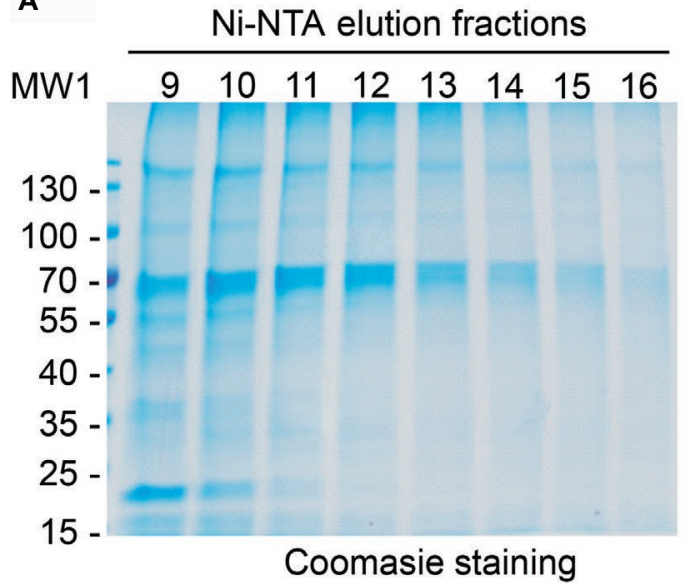

C
B Ni-NTA elution fractions

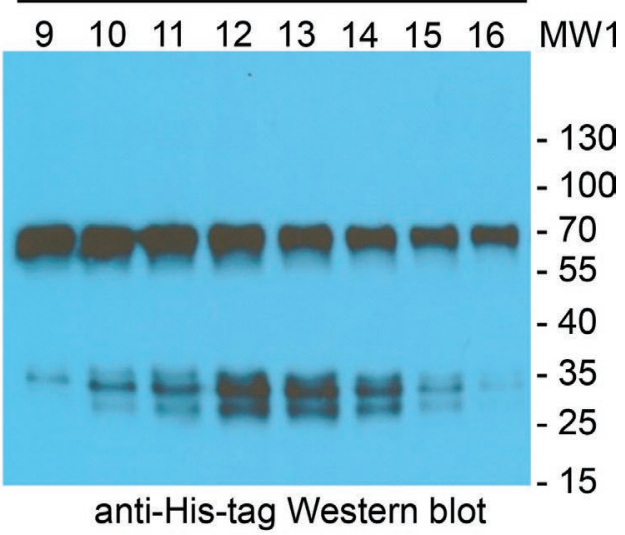

MFHR1 MFHR1 E10-16 E8-9
MW2

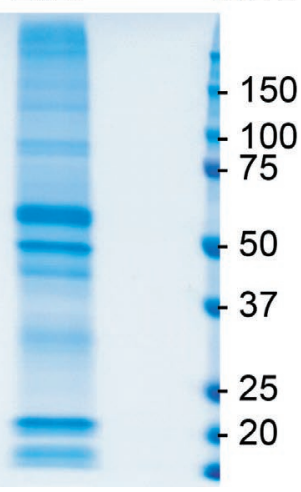

FIGURE 3 | Purification of mossMFHR1. (A) Coomassie staining of MFHR1 elution fractions 8-13, purified via Ni-NTA chromatography. (B) Western blot of the same elution fractions detected with anti-His-tag antibodies. MW1: PageRuler Prestained Protein Ladder (Thermo Fisher Scientific). (C) Coomassie staining of MFHR1 elution fraction pools (E8-9 and E10-16) and BSA as a reference. MW2: Precision Plus Protein ${ }^{\mathrm{TM}}$ Standard (BioRad). 
SCR2 and derived from FHR1 was occupied with glycans in only $35 \%$ of the peptides, while $65 \%$ were not modified (Figure 4B, Supplementary Figure 4). This is in agreement with the situation of FHR1 derived from human plasma where two different isoforms, FHR $1 \alpha$ and FHR1 $\beta, 37$ and $42 \mathrm{kDa}$, with one and two attached carbohydrate chains respectively, occur (Skerka and Zipfel, 2008). Approximately $86 \%$ of the glycosylated MFHR1 displayed the complex type N-glycan GnGn. Structures exhibiting terminal mannoses were below $1 \%$. Peptides with $\mathrm{N}$-glycans bearing $\beta 1,2$-linked xylose and $\alpha 1,3$-linked fucose were not detected. The lack of $\beta 1,2$-linked xylose and $\alpha 1,3$-linked fucose residues had been shown before for the parental line $\Delta x t / f t$ (Michelfelder et al., 2017). N-glycans decorated with Lewis A structures, the trisaccharide Fuc $\alpha 1-$ 4(Galß1-3)GlcNAc (Parsons et al., 2012), were detected in up to $14 \%$ of the product and on only one antenna of the sugar tree (GnAF). To sum up, moss-produced MFHR1 was complete and complex-type N-glycosylated.

\section{MossMFHR1 Displays Cofactor Activity as Early Regulatory Function in Complement Activation}

The first activity of $\mathrm{FH}$ within the regulation of the alternative complement pathway is its role as cofactor for FI-mediated cleavage of $\mathrm{C} 3 \mathrm{~b}$ in the fluid phase (cofactor activity of FH; Zipfel et al., 1999). To assess whether this important function is retained in the synthetic protein MFHR1, we compared mossMFHR1 to $\mathrm{FH}$ for their cofactor activity in a fluid-phase assay. We used mossFH because mossFH and plasmaFH exhibited comparable

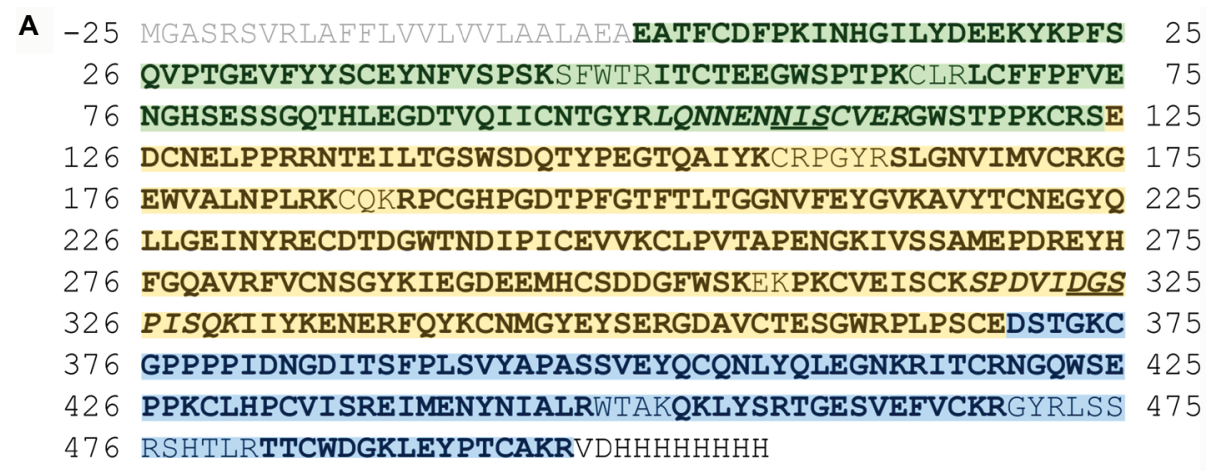

B

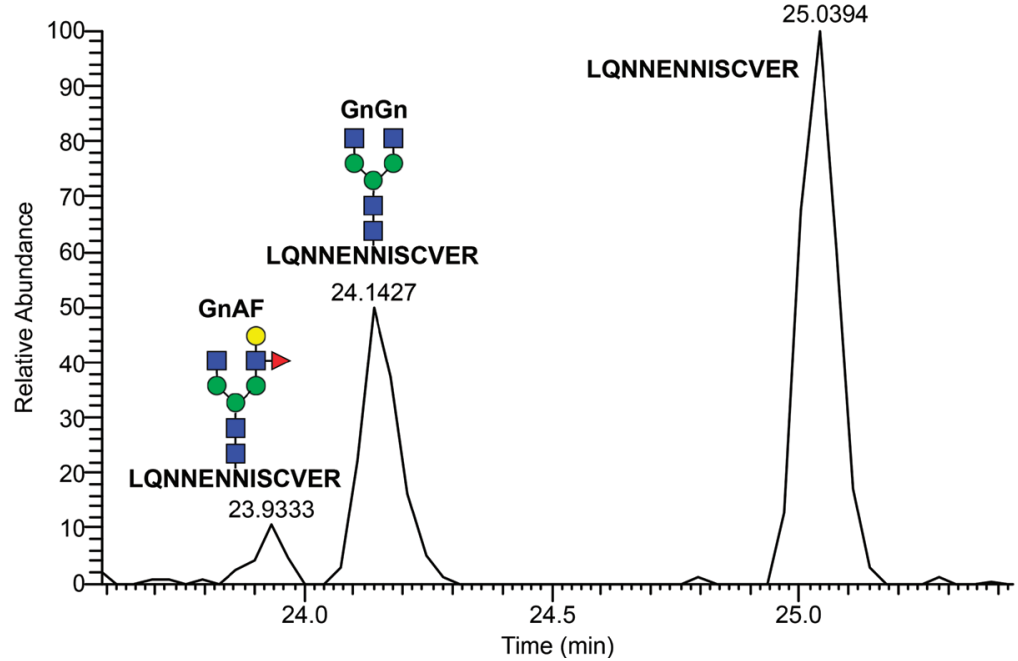

FIGURE 4 | Sequence and domain structure of MFHR1 and mass spectrometric sequence and N-glycosylation analyses. (A) Mature MFHR1 sequence (black) fused to the AP1-signal peptide (grey). The amino acid positions relating to the mature protein are given. Negative numbers refer to the signal peptide. The aminoterminal portion of MFHR1 is composed of the first two SCRs of FHR1 (green), followed by the catalytically active SCRs 1-4 from FH (yellow). The C-terminus includes the surface-binding SCRs 19-20 from FH (blue) followed by a His-tag. Peptides identified by mass spectrometry are shown in bold and the putative N-glycosylation site NIS (Asn108) and the deamidated site DGS (Asn323 $\rightarrow$ Asp323), are underlined, corresponding mass spectrometric detected tryptic peptides are shown in italics. (B) Elution profiles (extracted ion chromatogram, EIC) of the tryptic peptide ( ${ }_{102}$ LQNNENNISCVER $_{113}$ ) which flanks the glycosylation site NIS (Asn108) with and without N-glycosylation. Peak identity was confirmed by m/z-value and charge state on MS1- and by reporter ions on MS2-level (see Supplementary Figure 4 for further information). Peak quantification revealed an N-glycan occupancy at Asn108 of 35\%, which in total consisted of 86\% GnGn-, nearly $14 \%$ GnAF structures and $<1 \%$ of $\mathrm{N}$-glycans with terminal mannoses, all of them lacking plant specific core xylose and fucose. For the deamidated site (Asn323 $\rightarrow$ Asp323) no N-glycosylation was detectable. Gn: N-acetylglucosamine, A: galactose, F: Fucose - referring to the terminal sugar residues. 
cofactor activities before (Michelfelder et al., 2017). Moreover, we preferred mossFH for its homogeneity. In contrast to the recombinant mossFH, plasma-purified $\mathrm{FH}$ derives from several donors, thus being a mixture of $\mathrm{FH}$ variants with polymorphisms in some positions. The cleavage of $\mathrm{C} 3 \mathrm{~b}$ is indicated by a decrease of the $\mathrm{C} 3 \mathrm{~b} \alpha^{\prime}$-chain and occurrence of the cleavage products $\alpha^{\prime} 68-, \alpha^{\prime} 46-$, and $\alpha^{\prime} 43$. Cofactor activity was analyzed by SDS-PAGE and Coomassie staining (Figure $\mathbf{5 A}$ ), and the intensity of $\alpha^{\prime}$-chain bands was quantified by densitometry (Figure 5B). In a dose-dependent manner, mossMFHR1 and mossFH contributed to the FI-mediated degradation of the $\mathrm{C} 3 \mathrm{~b} \alpha^{\prime}$-chain into $\alpha^{\prime} 68-, \alpha^{\prime} 46-$, and $\alpha^{\prime} 43 \mathrm{kDa}$ fragments while the $\beta$-chain remained unchanged. Hence, MFHR1 showed comparable cofactor activity to $\mathrm{FH}$.

\section{MossMFHR1 Accelerates the Decay of the C3 Convertase and Inhibits Further Alternative Complement Pathway}

The so-called decay acceleration activity of mossMFHR1 was compared with plasma-derived $\mathrm{FH}$ (plasmaFH) and mossFH in vitro. $\mathrm{C} 3 \mathrm{~b}$ together with $\mathrm{FB}$ generates a complex that is cleaved by $\mathrm{FD}$ to generate the active $\mathrm{C} 3$ convertase $\mathrm{C} 3 \mathrm{bBb}$, which promotes the alternative pathway, intensifying the reaction via the amplification loop (Figure 1A). On the contrary, FH reduces the level of active $\mathrm{C} 3$ convertase $\mathrm{C} 3 \mathrm{bBb}$ by removing the $\mathrm{Bb}$ portion, thus inactivating the AP (Harris et al., 2005). As expected, mossMFHR1 accelerated the decay of the $\mathrm{C} 3$ convertase $\mathrm{C} 3 \mathrm{bBb}$ and even performed significantly better than plasmaFH and mossFH at higher concentrations of 10 and $25 \mathrm{nM}(p<0.05)$ (Figure 6).

\section{MossMFHR1 Inhibits the AP Activation in Human Blood}

To check the additional regulatory capacity of MFHR1 which derives from FHR1 domains, we measured the ability of mossMFHR1 to inhibit the formation of C5b-9, i.e. the terminal complement complex (TCC), after activation of the cascade with bacterial lipopolysaccharide (LPS) in human blood serum. In this assay, the regulatory activities on all AP levels are evaluated together. Increasing amounts of mossMFHR1 regulated LPS-induced AP activation and inhibited TCC formation efficiently and in most concentrations not significantly different from the therapeutic antibody Eculizumab (Figure 7); only at $32 \mathrm{nM}$ did the blocking antibody perform better than mossMFHR1 $(p<0.05)$. MossMFHR1 regulated the complement cascade and the formation of the TCC much more efficiently than plasmaFH. The complete inhibition of the AP was achieved by $56 \mathrm{nM}$ MFHR1; approximately, 22 times less MFHR1 was needed when compared to plasmaFH.

\section{DISCUSSION}

The complement system is a tightly regulated cascade that efficiently clears infectious agents and modified body cells and protects host tissues. Dysregulation of this delicately balanced cascade leads to infection and severe diseases such as atypical hemolytic uremic syndrome (aHUS), paroxysmal nocturnal hemoglobinuria (PNH), C3 glomerulopathy (C3G), age-related macular degeneration, and microangiopathic hemolytic anemia (Józsi et al., 2005). Complement factor $\mathrm{H}$ is a potent regulator of the alternative pathway and FH-replacement therapy could restore normal complement activity in the sera of aHUS and C3G patients (Michelfelder et al., 2017). Due to its high molecular mass and biochemical complexity, recombinant production of $\mathrm{FH}$ is far from trivial, thus no recombinant product is under clinical evaluation (Yang et al., 2018). Recently, mossFH showed full in vitro complement regulatory activity and decreased deposition of $\mathrm{C} 3$ cleavage products in preclinical studies in a murine model of $\mathrm{C} 3 \mathrm{G}$, indicating improved kidney function (Michelfelder et al., 2017). The therapy with Eculizumab, which

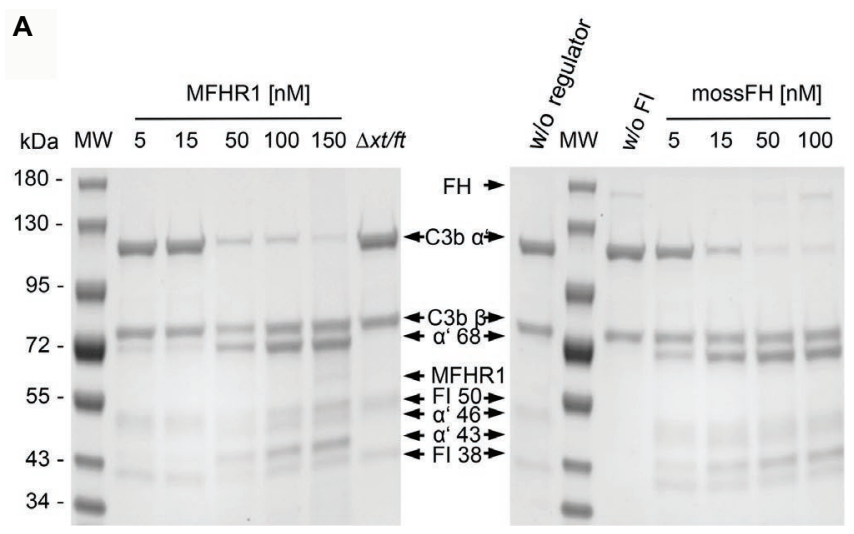

B

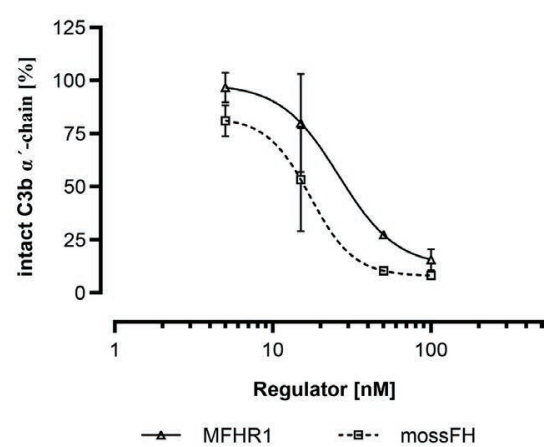

FIGURE 5 | The synthetic moss-produced complement regulator MFHR1 displays cofactor activity. (A) MossMFHR1 and mossFH act as cofactors for the FIdependent cleavage of $\mathrm{C} 3 \mathrm{~b}$ in the fluid phase in a dose-dependent manner. The cleavage products were detected after SDS-PAGE and Coomassie staining. MW: PageRuler Prestained Protein Ladder (Thermo Fisher Scientific); w/o regulator: no addition of MFHR1 or FH; w/o FI: no addition of Fl; $\Delta x t / f t:$ parental line, negative control. (B) MossMFHR1 shows similar cofactor activity compared to mossFH ( $p>0.05$, two-way ANOVA). The control without any regulator was set to $100 \%$. Data represent mean values and \pm SD from three independent experiments. Some error bars are shorter than the symbol. Analyses were done with GraphPad Prism software version 8.0 for Windows. 


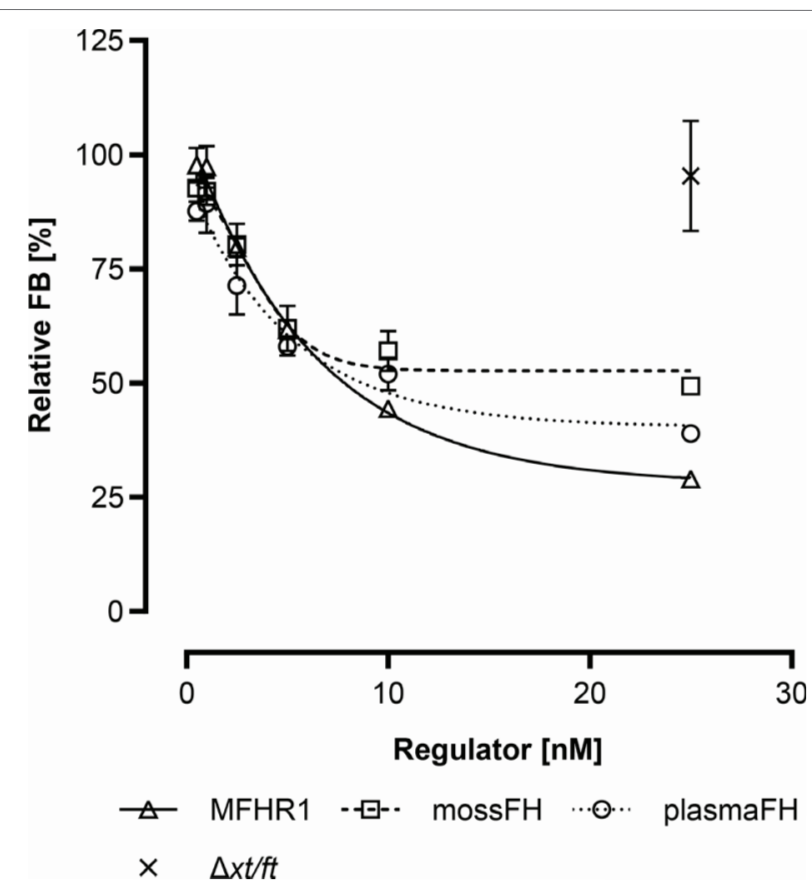

FIGURE 6 | MossMFHR1 displays decay acceleration activity on the C3 convertase $\mathrm{C} 3 \mathrm{bBb}$. Like mossFH and plasmaFH, mossMFHR1 accelerated the decay of $\mathrm{Bb}$ from $\mathrm{C} 3$ convertase $\mathrm{C} 3 \mathrm{bBb}$ complex in a dose-dependent manner. The OD at $450 \mathrm{~nm}\left(\mathrm{OD}_{450}\right)$ of preformed $\mathrm{C} 3 \mathrm{bBb}(\mathrm{C} 3 \mathrm{~b}+\mathrm{FB}+\mathrm{FD})$ without any regulator was set to $100 \%$. C3bBB OD 450 (only $\mathrm{C} 3 \mathrm{~b}+\mathrm{FB}$ without any FD and regulator) was set to $0 \%$. Purified extract of the parental moss strain $\Delta x t / f t$ was included as a control, in equal amounts to the volume of MFHR1 used for the highest concentration. Data represent mean values and $\pm S D$ from three replicates and were analyzed with two-way ANOVA followed by Bonferroni test. Some error bars are shorter than the symbol. Analyses were done with GraphPad Prism software version 8.0 for Windows.

binds C5 and inhibits its activation, improved disease progression, survival, and quality of life in patients with aHUS and PNH but showed partial response only in some patients suffering from C3G, most likely due to the uncontrolled over-activation of the cascade in steps previous to Eculizumab's point of action (Bomback et al., 2012). Thus, recombinant proteins modulating the complement system on multiple levels might be key to the development of new therapeutics to treat complement-related disorders. MFHR1, a novel synthetic multitarget complement inhibitor designed to combine the terminal pathway regulatory activity of FHR1 with the regulatory domains for $\mathrm{C} 3$ level control and binding affinity to host cell surfaces of $\mathrm{FH}$, was synthesized in a proof-of-concept study with transiently transfected insect cells and shown to be a promising multilevel complement regulator (Michelfelder et al., 2018). This study demonstrated that MFHR1 can achieve the same complement regulatory activity as plasmaFH at much lower concentrations. Being FH a very abundant serum protein with concentrations of approximately $500 \mu \mathrm{g} / \mathrm{ml}$, the amount of protein needed per patient is important for the feasibility of the treatment. Baculovirus-infected insect cells are used for heterologous protein expression widely for two reasons: availability of two strong promoters which drive target protein expression to high levels

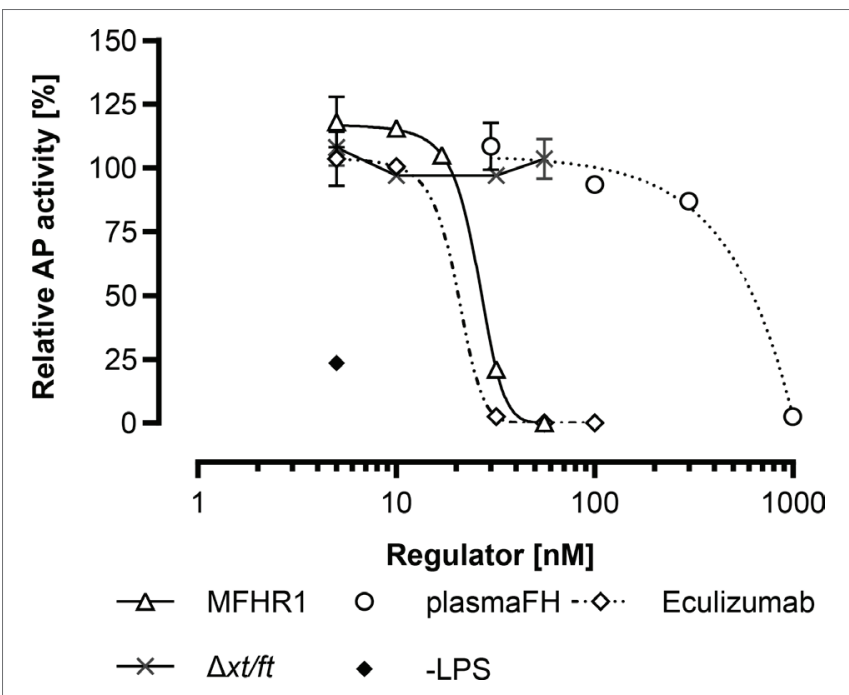

FIGURE 7 | MossMFHR1 inhibits the AP activity after induction of the alternative pathway in human serum. The C5b-9 complex formation was measured by ELISA after LPS-induced AP activation. Data represent mean values and bars show the range of duplicates and were analyzed with twoway ANOVA followed by Bonferroni test. The serum without regulators was set to $100 \%$ and heat-inactivated serum to $0 \%$. Activity in wells not coated with LPS (-LPS) was used as a reference. Purified extract of the parental moss strain $\Delta x t / f t$ was included as a negative control, in equal amounts to the volume of MFHR1 used. Analyses were done with GraphPad Prism software version 8.0 for Windows.

(Scholz and Suppmann, 2017) and lepidopteran cell lines that can perform post-translational modifications and grow to high cell densities (Berger et al., 2004; Van Oers et al., 2015). On the other hand, there are several drawbacks including demanding and expensive culture conditions (Gecchele et al., 2015), batchto-batch inconsistency due to the lot-to-lot variability of media (Chan and Reid, 2016), the need of large volumes of viruses to scale up protein production, different glycosylation pattern (paucimannosidic N-glycans) than humans (Shi and Jarvis, 2007), potential cell lysis, and degradation of protein of interest caused by viral infection (Broadway, 2012). Therefore, after demonstrating the bioactivity of insect-cell expressed MFHR1 protein, we now aimed to establish a stable production process for MFHR1 in the moss bioreactor. This system proved its validity as a biopharmaceutical production host by successfully completing the phase I clinical trial for moss-aGal (Reski et al., 2018). Moreover, it was the first system to succeed in the stable production of active recombinant human FH (Büttner-Mainik et al., 2011; Michelfelder et al., 2017).

After the characterization of transgenic moss lines in terms of growth performance and MFHR1 production levels in bioreactors, the line P1 was found to be most promising with production levels of $100 \mu \mathrm{g}$ MFHR1/g FW and a 54-time increment of the biomass within 9 days of cultivation in a 5 -L bioreactor.

The endogenous actin 5 promoter, and the 5' UTR including its intron, is a valuable tool for the production of pharmaceutically interesting proteins in P. patens (Baur et al., 2005a,b; Weise et al., 2006, 2007; Büttner-Mainik et al., 2011; Michelfelder et al., 2017). For proteins expressed under the control of this 
promoter, a temporal increase in the production of the protein of interest in $P$. patens could be achieved by the addition of auxin (data not shown). This effect could be shown here as the addition of the synthetic auxin NAA increased MFHR1 levels. Auxin also stimulated the ACT7-GUS reporter in Arabidopsis thaliana (Kandasamy et al., 2001). To attain an increase in recombinant protein yield, however, auxin concentration and time of exposition had to be adapted to each protein of interest and culture conditions.

According to mass spectrometry, mossMFHR1 is completely and correctly synthesized with a moss-derived signal peptide (Schaaf et al., 2004) and properly processed as demonstrated before for moss-produced recombinant human VEGF and FH (Gitzinger et al., 2009; Büttner-Mainik et al., 2011; Michelfelder et al., 2017). In addition, complex-type N-glycosylation of mossMFHR1 was confirmed by MS-based glycopeptide analysis. The site NGS originated from $\mathrm{FH} \mathrm{SCR}$ was not glycosylated, but deamidated to DGS, as observed before for both, human plasma-purified as well as moss-produced FH (Fenaille et al., 2007; Michelfelder et al., 2017). The other MFHR1 N-glycan site, located in FHR1-derived SCR2, was occupied in approximately $35 \%$ of the molecules predominantly with GnGn N-glycans. A small portion harbored monoantennary Lewis A structures. The moss $\alpha 1,4$ fucosyltransferase and $\beta 1,3$ galactosyltransferase responsible for this modification have already been identified and could be further eliminated by knocking out the responsible genes as it was already achieved for asialo-EPO production in moss (Parsons et al., 2012). N-glycans with terminal mannoses were less than $1 \%$ and as expected from the glyco-engineered $\Delta x t / f t$ parental line, putatively immunogenic $\beta 1,2$-linked xylose and $\alpha 1,3$-linked fucose never appeared. The fact that the majority of mossMFHR1 molecules was not glycosylated is in full agreement with the situation described for human FHR1 (Skerka and Zipfel, 2008). Considering the different aspects of glycosylation, the mossMFHR1 presented here provides optimal conditions for a safe, non-immunogenic pharmaceutical.

Having proven its structural integrity, the different proposed functions of mossMFHR1 were subsequently tested. Aiming at a multilevel activity from combining the relevant functional domains of FHR1 and FH, we checked both, the functions of $\mathrm{FH}$ domains, by controlling the early stages of AP activation (proximal part) in the fluid phase and of FHR1 in the terminal part, blocking TCC formation on target structures. FH is inhibiting the activation of the complement cascade on two levels: as a cofactor for FI-mediated cleavage of $\mathrm{C} 3 \mathrm{~b}$ and in accelerating the decay of the crucial enzyme of complement activation, the C3 convertase. Both functions were executed by mossMFHR1 in a similar or even more efficient way compared to the full-length mossFH (Michelfelder et al., 2017) or human plasma-purified FH. MossMFHR1 degraded the C3 convertase like plasmaFH and mossFH at low concentrations and performed significantly better than both $\mathrm{FH}$ versions at higher concentrations. MFHR1 activity for inhibiting the terminal pathway was measured as decrease of C5b-9 (TCC) formation and compared to the activity of the C5-inhibiting antibody Eculizumab as well as plasmaFH. MossMFHR1 inhibited TCC formation in a similar manner as Eculizumab and 22 times more efficiently than plasmaFH. These results are in accordance with those obtained with the insect cell-derived MFHR1 (Michelfelder et al., 2018) and a similar fusion protein published recently (Yang et al., 2018). The improved activity compared to native $\mathrm{FH}$ might be explained not only by the combined activity at different levels of the alternative pathway but also by the formation of MFHR1 homodimers deriving from the FHR1 dimerization domain included in MFHR1 (Michelfelder et al., 2018; Yang et al., 2018).

These encouraging results, the structural integrity and increased activity combined with a smaller molecule size, strongly recommend the initiation of large-scale cultivation for proving the mossMFHR1's in vivo therapeutic activity. In summary, mossMFHR1 showed its high potential to become a new and indispensable drug for patients with complement-associated disorders.

\section{MATERIALS AND METHODS}

\section{Construct Generation}

For efficient production of MFHR1, the vector pAct5-MFHR1 was used, where the expression of the MFHR1 coding sequence is driven by the $5^{\prime}$ region, including the $5^{\prime}$ intron, of the PpActin 5 gene (Weise et al., 2006). The CaMV 35S terminator preceded by an $8 \mathrm{x}$ His-tag and a SalI restriction site was amplified from the pRT_VEGF 121 plasmid (Koprivova et al., 2004). In addition, this plasmid includes an hpt cassette for selection of transformed plants with hygromycin (Supplementary Figure 5).

The targeting of the mossMFHR1 to the secretory pathway for proper posttranslational modifications was driven by the aspartic proteinase signal peptide from $P$. patens, PpAP1 (Schaaf et al., 2004, 2005). Its coding sequence was amplified from the plasmid pFH (Büttner-Mainik et al., 2011) with the primers XhoI_MFHR1_F (5'-TCTCGAGATGGGGGCATCGAGG-3') and AP_MFHR1_R (5'-ATCACAAAATGTTGCTTCTGCCTCAG CTAAGGC- $3^{\prime}$ ). The coding sequence for the MFHR1 was amplified from pFastbac-MFHR1 (Michelfelder et al., 2018) with the primers AP_MFHR1_F (5'-GAGGCAGAAGCAACATTTT GTGATTTTCCAAAAATAAACC-3') and SalI_MFHR1_R (5'-TGTCGACTCTTTTTGCACAAGTTGGATACTC-3'). The signal peptide and the MFHR coding sequence were assembled via two-template PCR with the primers XhoI_MFHR1_F and SalI_MFHR1_R and cloned into the expression vector via XhoI and SalI restriction sites.

All amplifications were performed by phusion DNA polymerase (Thermo Fisher Scientific, Waltham, MA, USA)-based PCR.

\section{Plant Material and Cell Culture}

Physcomitrella patens (Hedw.) Bruch \& Schimp was cultivated as described previously (Frank et al., 2005). The MFHR1-producing moss lines were obtained by stable transformation of the $\Delta x t /$ $f t$ moss line, in which the $\alpha 1,3$ fucosyltransferase and the $\beta 1,2$ xylosyltransferase genes have been disrupted via homologous recombination. Transfection was performed with $40 \mu \mathrm{g}$ of linearized MFHR1 construct per reaction as described before (Decker et al., 2015). Subsequently, selection of stable transformants on solidified Knop medium containing $25 \mathrm{mg} / \mathrm{L}$ hygromycin was performed as described previously (Decker et al., 2015). 
Plants surviving the selection with hygromycin were screened for the presence of the transgene in the moss genome by PCR, as described before (Parsons et al., 2012), using the primers MFHR1_fwd (5'-GAAGGATGGTCACCAACACC- $\left.3^{\prime}\right)$ and MFHR1_rev (5'-CATTGGTCCATCCATCTGTG- $\left.3^{\prime}\right)$. The production of the protein of interest was tested via ELISA. For this purpose, approximately $10 \mathrm{mg}$ of plant material were picked from colonies growing on Knop solid medium and transferred to 2-ml tubes with one tungsten carbide (Qiagen, Hilden, Germany) and one glass (Roth, Karlsruhe, Germany) beads, diameter $3 \mathrm{~mm}$. After the addition of $120 \mu \mathrm{l}$ extraction buffer $(408 \mathrm{mM} \mathrm{NaCl}$, $60 \mathrm{mM} \mathrm{Na} \mathrm{HPO}_{4}, 10.56 \mathrm{mM} \mathrm{K \textrm {K } _ { 2 }} \mathrm{PO}_{4}, 60 \mathrm{mM}$ EDTA, pH 7.4 and $1 \%$ protease inhibitor (P9599, Sigma-Aldrich), plant material was homogenized for $1 \mathrm{~min}$ by the use of a mixer mill (MM 400, Retsch, Haan, Germany) at $30 \mathrm{~Hz}$ and subsequently sonicated for $10 \mathrm{~min}$ in a ultrasound bath (Bandelin Sonorex RK52). Extracts were analyzed via ELISA as described before (Büttner-Mainik et al., 2011), but using the anti-FH antibody GAU 018-03-02 (Thermo Fisher Scientific) as capture antibody 1:2,000 in coating buffer, and using FH as standard protein (Calbiochem, San Diego, CA, USA) for the screening of MFHR1-producing plants. Under these conditions, the ELISA has a linear response from 1 to $64 \mathrm{ng} / \mathrm{ml}$. For the quantification of MFHR1 produced by plants grown in liquid media, the protein extraction was performed as described above, but the plant material was first vacuum-filtrated, frozen, and disrupted frozen before the addition of the buffer.

For production of MFHR1, the P1 line was cultivated at $\mathrm{pH} 4.5$ in a $5 \mathrm{~L}$ photobioreactor as described previously (Hohe and Reski, 2005), with continuous light at $350 \mu \mathrm{E}$ intensity. Daily from day 6 to day 8, 2 L suspensions were harvested and replaced by fresh medium. Plant material was vacuumfiltrated and shock-frozen in $\mathrm{N}_{2}$, and stored at $-80^{\circ} \mathrm{C}$ until further processing. At day 8, after harvesting, $250 \mu \mathrm{l} 100 \mathrm{mM}$ naphthaleneacetic acid (NAA, Sigma) was added to the bioreactor to reach a final concentration of $5 \mu \mathrm{M}$ NAA. At day 9, the whole culture was harvested.

\section{Purification of Recombinant MFHR1}

Frozen plant material was resuspended in binding buffer $(0.75 \mathrm{M}$ $\mathrm{NaCl}, 75 \mathrm{mM} \mathrm{Na}_{2} \mathrm{HPO}_{4}, 10 \mathrm{mM}$ Imidazole, $1 \%$ protease inhibitor, $\mathrm{pH} 8.0$ ) in a ratio plant material:buffer $1: 4$, and homogenized for $10 \mathrm{~min}$ with an Ultra-Turrax at $10,000 \mathrm{rpm}$ on ice. After centrifugation, the supernatant was filtrated through $1 \mu \mathrm{m}$ polyethersulfon (PES) filters (Whatman, GE Healthcare UK Limited, Buckinghamshire, UK) and subsequently through $0.22 \mu \mathrm{m}$ PES filters (Roth).

Chromatography was performed using an ÄKTA system (GE Healthcare, Uppsala, Sweden) at a flow rate of $1 \mathrm{ml} / \mathrm{min}$. The filtered cellular extract was applied to a $1 \mathrm{ml}(\mathrm{CV})$ HisTrap FF column (GE-Healthcare). After washing with $30 \mathrm{CV}$ binding buffer supplemented with $3 \%$ buffer B $(500 \mathrm{mM} \mathrm{NaCl} ; 500 \mathrm{mM}$ imidazole; $100 \mathrm{mM} \mathrm{Na} \mathrm{HPO}_{4}$; $\mathrm{pH}$ 8.0), elution was performed in a gradient of $3-100 \%$ of buffer $\mathrm{B}$ in $9 \mathrm{CV}$ and recovered in $0.5 \mathrm{ml}$ fractions. Fractions containing the protein of interest with a negligible amount of contaminant proteins were pooled (fractions 10-16), dialyzed against DPBS (Gibco ${ }^{\circledR}$ by Life Technologies,
Darmstadt, Germany) in two Slide-A-Lyzer ${ }^{\circledR}$ MINI Dialysis Devices, $20 \mathrm{~K}$ MWCO and concentrated using Vivaspin membrane filter devices (Sartorius AG, Goettingen, Germany) with a $10 \mathrm{kD}$ MWCO. Subsequently, the product was aliquoted, shock frozen in liquid $\mathrm{N}_{2}$, and stored at $-80^{\circ} \mathrm{C}$ until further analysis.

\section{Protein Quantification}

The concentration of mossMFHR1 used for activity assays was measured via ELISA, using the same antibodies and protocol performed for mossFH as described above. As standard for the ELISA, a batch of purified mossMFHR1 was used in which its concentration was determined via band densitometry (Quantity One, Bio-Rad, Munich, Germany) after SDS-PAGE (Ready Gel Tris-HCl, Bio-Rad) and Coomassie staining. The sandwich ELISA using this MFHR1 standard protein has a linear response between 1 and $64 \mathrm{ng} / \mathrm{ml}$. Electrophoretic separation of proteins was carried out in 10\% SDS-polyacrylamide gels (Ready Gel Tris-HCl; BioRad) at 120 V. Subsequently, gels were stained with PageBlue ${ }^{\circledR}$ Protein Staining Solution (PageBlue $^{\mathrm{TM}}$, Thermo Fisher Scientific). For Western blot analysis, SDS-PAGE gel was blotted to polyvinylidene fluoride (PVDF) membranes (Immobilon-P; Millipore, Bedford, MA, USA) in a Trans-Blot SD Semi-Dry Electrophoretic Cell (Bio-Rad) for $1 \mathrm{~h}$ with $1 \mathrm{~mA} / \mathrm{cm}^{2}$ membrane. Immunoblotting was performed using mouse anti-His antibodies (MAB050, R\&D Systems, Minneapolis, MN, USA) as primary and sheep anti-mouse antibodies coupled to peroxidase (NA931, Amersham ECL ${ }^{\mathrm{TM}}$, GE Healthcare) as secondary antibody in a 1:500 and 1:10,000 dilution respectively, followed by chemiluminescence development (ECL ${ }^{\mathrm{TM}}$ Advance Western Blotting Detection Kit, GE Healthcare) following the manufacturer's instructions.

\section{Glycopeptide Analysis}

Glycopeptide analysis was performed from samples purified via Ni-NTA. These were mixed 1:1 with $2 \mathrm{x}$ sample loading buffer (Bio-Rad) with $50 \mathrm{mM} \mathrm{DTT}$, incubated for $5 \mathrm{~min}$ at $95^{\circ} \mathrm{C}$ and after cooling down to room temperature the samples were S-alkylated. Electrophoretic separation and Coomassie staining was performed as described above, and the bands corresponding to mossMFHR1 (monitored by a parallel Western blot) were cut and digested with trypsin overnight. Tryptic peptides were extracted first with $100 \%$ acetonitrile (ACN) followed by $5 \%$ formic acid and glycopeptide enrichment procedure was modified after (Kolarich et al., 2012) using HILIC HyperSep ${ }^{\text {TM }}$ Tips (Thermo Fisher Scientific). Gel extracts were dried in a vacuum concentrator and dissolved in $100 \mu \mathrm{l}$ HILIC binding buffer (85\% Acetonitrile, $15 \mathrm{mM}$ ammonium acetate, $\mathrm{pH}$ 3.5). Each HILIC tip was equilibrated with $20 \mu \mathrm{l}$ binding buffer. About $100 \mu \mathrm{l}$ sample was loaded by up and down pipetting for 40 times. The flow-through was collected and dried in a vacuum concentrator. The loaded HILIC tip was washed with $20 \mu \mathrm{l}$ binding buffer by up and down pipetting for 20 times. Glycopeptides were eluted in $20 \mu \mathrm{l} 15 \mathrm{mM}$ ammonium acetate ( $\mathrm{pH} 3.5)$ and dried by vacuum concentration. The dried flow-through fraction was dissolved in $100 \mu \mathrm{l} 0.1 \%$ 
formic acid and desalted using C18 StageTips (Thermo Fisher Scientific). C18 Tips were equilibrated successively with $100 \mu \mathrm{l}$ $0.1 \%$ formic acid, next with $100 \mu 180 \%$ ACN with $0.1 \%$ formic acid and finally again with $100 \mu \mathrm{l} \quad 0.1 \%$ formic acid. The dissolved flow-through was loaded, washed with $100 \mu \mathrm{l} 0.1 \%$ formic acid, and eluted in $100 \mu \mathrm{l} \mathrm{ACN}$ with $0.1 \%$ formic acid. The elution fraction was dried in a vacuum concentrator. Both the HILIC and the C18 eluates were dissolved in $0.1 \%$ formic acid and measured using the UltiMate 3,000 RSLCnano system (Dionex LC Packings/Thermo Fisher Scientific, Dreieich, Germany) coupled online to a QExactive Plus instrument (Thermo Fisher Scientific, Bremen, Germany). For the UHPLC systems, a C18-precolumn (Ø $0.3 \mathrm{~mm}$, length $5 \mathrm{~mm}$; PepMap, Thermo Fisher Scientific) and an Acclaim ${ }^{\circledR}$ PepMap analytical column (ID: $75 \mu \mathrm{m}, 500 \mathrm{~mm}$, length $2 \mathrm{~m}, 100 \AA$, Dionex LC Packings/Thermo Fisher Scientific) were used. Washing and pre-concentration of samples took place on a C18-precolumn with $0.1 \%$ formic acid (solvent A) for $5 \mathrm{~min}$ before peptides entering the analytical column. With a flow rate of $250 \mathrm{nl} /$ min, peptide separation was performed applying a 45 -min gradient of $4-40 \%$ solvent B ( $0.1 \%$ formic acid $/ 86 \%$ acetonitrile) in $30 \mathrm{~min}$ and $40-95 \%$ solvent B in $5 \mathrm{~min}$. After each gradient, the analytical column was washed with $95 \%$ solvent B for $5 \mathrm{~min}$ and re-equilibrated for $15 \mathrm{~min}$ with $4 \%$ solvent B. MS/ MS analyses were performed on multiply charged peptide ions. To automatically switch between MS (max. of $1 \times 10$ ions) and MS/MS the instrument operation took place in the datadependent mode. After MS scan, a maximum of 12 precursors were selected for MS/MS scans using HCD with normalized collision energy of $35 \%$. The mass range for MS was $\mathrm{m} / \mathrm{z}=375-1,700$ and resolution was set to 70,000 . MS parameters were as follows: spray voltage $1.5 \mathrm{kV}$ and ion transfer tube temperature $200^{\circ} \mathrm{C}$. Raw data analysis was performed using Mascot Distiller V2.5.1.0 (Matrix Science, USA), and the peak lists were searched with Mascot V2.6.0 against an in-house database containing all P. patens V1.6 protein models (Zimmer et al., 2013) as well as the MFHR1 sequence.

For database searching, the following parameters were used: peptide mass tolerance: $5 \mathrm{ppm}$, MS/MS mass tolerance: $0.02 \mathrm{Da}$, enzyme: trypsin with maximum two missed cleavages, variable modifications: Gln- > to pyroGlu (N-term. Q) -17.026549 Da, oxidation (M) and carbamidomethyl (C). +57.021464 Da, Hydroxyproline (P) +15.994915 Da. Quantitation of peptides was done with Excalibur Qual Browser V2.2.44 (Thermo Fisher Scientific) employing manual peak area integration of extracted ion chromatograms. For all glycopeptides identified, the presence of the GlcNAc-specific reporter ions (Halim et al., 2014) was inspected in the corresponding MS/MS spectra to confirm the presence of glycan structures. The following $\mathrm{m} / \mathrm{z}$-values were expected: LQNNENNISCVER $\left[\mathrm{M}+2 \mathrm{H}^{+}\right]:$795.3704, LQNNENNISCVER_ GnGn $\left[\mathrm{M}+3 \mathrm{H}^{+}\right]$: 963.4081, LQNNENNISCVER_GnAF $\left[\mathrm{M}+3 \mathrm{H}^{+}\right]$: 1066.1116.

\section{Cofactor Activity}

C3b proteolytic degradation regulatory activity of mossMFHR1 and plasmaFH was compared in a fluid phase cofactor assay modified from Michelfelder et al. (2017). Briefly, in a $20 \mu \mathrm{l}$ reaction, increasing doses of mossMFHR1 or plasmaFH, and corresponding maximal volume of the parental plant $\Delta x t / f t$ purified extract as control, were incubated with $2 \mu \mathrm{g}$ C3b and $500 \mathrm{ng}$ complement factor I (FI) (CompTech, Texas, USA) in PBS at $37^{\circ} \mathrm{C}$ for $30 \mathrm{~min}$. The reaction was stopped by the addition of sample loading buffer (Bio-Rad) under reducing conditions (50 mM DTT, NuPAGE ${ }^{\mathrm{rm}}$, Thermo Fisher Scientific). The FH and FI catalyzed proteolytic cleavage of $\mathrm{C} 3 \mathrm{~b}$ into $\mathrm{iC} 3 \mathrm{~b}$ was analyzed by visualizing the $\alpha$-chain cleavage fragments ''68 and $\alpha^{\prime} 43$ by SDS-Page in 10\% SDS-polyacrylamide gels and Coomassie staining. The remaining intact $\alpha$-chain was quantified by band densitometry (Quantity One, Bio-Rad).

\section{Decay Acceleration Activity}

The ability of mossMFHR1 to displace the fragment $\mathrm{Bb}$ from the preformed $\mathrm{C} 3$ convertase complex $\mathrm{C} 3 \mathrm{bBb}$ was measured by ELISA as described previously (Michelfelder et al., 2017). Purified C3b (CompTech) was immobilized on Maxisorb plates and $400 \mathrm{ng}$ Factor B and $25 \mathrm{ng}$ Factor D (CompTech) in phosphate buffer (containing $2 \mathrm{mM} \mathrm{NiCl}_{2}, 25 \mathrm{mM} \mathrm{NaCl}$, and $4 \%$ BSA) was added to the wells and incubated for $2 \mathrm{~h}$ at $37^{\circ} \mathrm{C}$ to generate $\mathrm{C} 3 \mathrm{bBb}$ complex. Various doses of MFHR1, mossFH, plasmaFH, or $\Delta x t / f t$ were added and incubated for $30 \mathrm{~min}$ at $37^{\circ} \mathrm{C}$. Afterward, intact $\mathrm{C} 3 \mathrm{bBb}$ complexes were measured by FB-specific antibody (1:2,000; Merck, Darmstadt, Germany), followed by HRP-conjugated rabbit anti-goat (1:5,000; Dako, Hamburg, Germany). The $\mathrm{OD}$ at $450 \mathrm{~nm}\left(\mathrm{OD}_{450}\right)$ was obtained after the incubation with TMB Substrate. The $\mathrm{OD}_{450}$ of preformed $\mathrm{C} 3 \mathrm{bBb}(\mathrm{C} 3 \mathrm{~b}+\mathrm{FB}+\mathrm{FD})$ without any regulator was set to $100 \%$. $\mathrm{C} 3 \mathrm{bBB} \mathrm{OD}_{450}$ (only $\mathrm{C} 3 \mathrm{~b}+\mathrm{FB}$ without any $\mathrm{FD}$ and regulator) was set to $0 \%$.

\section{Determination of AP-Activity in Human Serum}

The ability of mossMFHR1 to inhibit the AP activity in normal human serum (NHS) was determined by measuring the Terminal Complement Complex formation inhibition via ELISA as previously described (Michelfelder et al., 2018). In this ELISAbased method, the amount of active C5b-9 formation is measured during incubation of serum in wells pre-coated with lipopolysaccharide (LPS) in the presence of AP-pathway-specific conditions. The amount of bound C5b-9, detected via specific antibodies, is directly proportional to the activity of the AP. Extracts from the parental plant $\Delta x t / f t$ were used as negative controls. The $\mathrm{OD}_{450}$ obtained for samples with heat-inactivated serum instead of NHS were set to $0 \%$ and samples without any addition of regulators were set to $100 \%$ of C $5 b-9$ formation.

\section{STATISTICAL ANALYSIS}

Analyses were done with the GraphPad Prism software version 8.0 for Windows (GraphPad software, San Diego, California, USA; www.graphpad.com). 


\section{DATA AVAILABILITY}

All datasets generated for this study are included in the manuscript and/or the Supplementary Files.

\section{AUTHOR CONTRIBUTIONS}

OT and JP purified the protein and performed the activity tests. JP carried out the moss cultures in the bioreactor. LB and $\mathrm{SH}$ performed the mass spectrometric analysis. PK cloned the expressing vector and transformed $P$. patens with it. CB-S screened the putative producing lines. SM cloned the coding sequence and set up the activity test protocols. OT, JP, $\mathrm{KH}$, $\mathrm{PZ}, \mathrm{RR}$ and ED designed the study and wrote the manuscript.

\section{FUNDING}

This work was supported by the Excellence Initiative of the German Federal and State Governments (GSC-4 to OT, EXC

\section{REFERENCES}

Baur, A., Kaufmann, F., Rolli, H., Weise, A., Luethje, R., Berg, B., et al. (2005a). A fast and flexible PEG-mediated transient expression system in plants for high level expression of secreted recombinant proteins. J. Biotechnol. 119, 332-342. doi: 10.1016/j.jbiotec.2005.04.018

Baur, A., Reski, R., and Gorr, G. (2005b). Enhanced recovery of a secreted recombinant human growth factor using stabilizing additives and by coexpression of human serum albumin in the moss Physcomitrella patens. Plant Biotechnol. J. 3, 331-340. doi: 10.1111/j.1467-7652.2005.00127.x

Berger, I., Fitzgerald, D. J., and Richmond, T. J. (2004). Baculovirus expression system for heterologous multiprotein complexes. Nat. Biotechnol. 22, 1583-1587. doi: $10.1038 / \mathrm{nbt} 1036$

Bomback, A. S., Smith, R. J., Barile, G. R., Zhang, Y., Heher, E. C., Herlitz, L., et al. (2012). Eculizumab for dense deposit disease and C3 glomerulonephritis. Clin. J. Am. Soc. Nephrol. 7, 748-756. doi: 10.2215/CJN.12901211

Broadway, N. (2012). Recombinant protein pxpression: vector-host systems. Mater. Methods 2:123. doi: 10.13070/mm.en.2.123

Büttner-Mainik, A., Parsons, J., Jérôme, H., Hartmann, A., Lamer, S., Schaaf, A., et al. (2011). Production of biologically active recombinant human factor H in Physcomitrella. Plant Biotechnol. J. 9, 373-383. doi: 10.1111/j. 1467-7652.2010.00552.x

Cataland, S. R., and Wu, H. M. (2014). Diagnosis and management of complement mediated thrombotic microangiopathies. Blood Rev. 28, 67-74. doi: 10.1016/j. blre.2014.01.003

Chan, L. C. L., and Reid, S. (2016). Development of serum-free media for lepidopteran insect cell lines. Methods in Molecular Biology 350, 161-196.

De Córdoba, S. R., and De Jorge, E. G. (2008). Translational mini-review series on complement factor $\mathrm{H}$ : genetics and disease associations of human complement factor H. Clin. Exp. Immunol. 151, 1-13. doi: 10.1111/j. 1365-2249.2007.03552.x

Decker, E. L., Parsons, J., and Reski, R. (2014). Glyco-engineering for biopharmaceutical production in moss bioreactors. Front. Plant Sci. 5:346. doi: $10.3389 /$ fpls.2014.00346

Decker, E. L., and Reski, R. (2012). Glycoprotein production in moss bioreactors. Plant Cell Rep. 31, 453-460. doi: 10.1007/s00299-011-1152-5

Decker, E. L., Wiedemann, G., and Reski, R. (2015). Gene targeting for precision glyco-engineering: production of biopharmaceuticals devoid of plant-typical glycosylation in moss bioreactors. Glyco-engineering: Methods in Molecular Biology 1321, 213-224. doi: 10.1007/978-1-4939-2760-9_15
294 to RR); and a grant from the German Federal Ministry of Education and Research (BMBF 0313852C to RR). RR and $\mathrm{KH}$ received research funding by Greenovation Biotech $\mathrm{GmbH}$.

\section{ACKNOWLEDGMENTS}

We thank Dagmar Krischke, Astrid Wäldin, Christina Jaeger, Natalia Ruiz Molina, and Melanie Heck for their support of this work, Bettina Warscheid for the possibility to use the mass spectrometer, Anne Katrin Prowse for language editing, and Greenovation for the $\Delta x t / f t$ moss line.

\section{SUPPLEMENTARY MATERIAL}

The Supplementary Material for this article can be found online at: https://www.frontiersin.org/articles/10.3389/fpls.2019.00260/ full\#supplementary-material

Fenaille, F., Le Mignon, M., Groseil, C., Ramon, C., Riandé, S., Siret, L., et al. (2007). Site-specific N-glycan characterization of human complement factor H. Glycobiology 17, 932-944. doi: 10.1093/glycob/cwm060

Frank, W., Decker, E. L., and Reski, R. (2005). Molecular tools to study Physcomitrella patens. Plant Biol. 7, 220-227. doi: 10.1055/s-2005-865645

Fridkis-Hareli, M., Storek, M., Mazsaroff, I., Risitano, A. M., Lundberg, A. S., Horvath, C. J., et al. (2011). Design and development of TT30, a novel C3d-targeted C3/C5 convertase inhibitor for treatment of human complement alternative pathway-mediated diseases. Blood 118, 4705-4713. doi: 10.1182/ blood-2011-06-359646

Fritsche, L. G., Igl, W., Bailey, J. N. C., Grassmann, F., Sengupta, S., BraggGresham, J. L., et al. (2016). A large genome-wide association study of age-related macular degeneration highlights contributions of rare and common variants. Nat. Genet. 48, 134-143. doi: 10.1038/ng.3448

Fritsche, L. G., Lauer, N., Hartmann, A., Stippa, S., Keilhauer, C. N., Oppermann, M., et al. (2010). An imbalance of human complement regulatory proteins CFHR1, CFHR3 and factor $\mathrm{H}$ influences risk for age-related macular degeneration (AMD). Hum. Mol. Genet. 19, 4694-4704. doi: 10.1093/hmg/ddq399

Gecchele, E., Merlin, M., Brozzetti, A., Falorni, A., Pezzotti, M., and Avesani, L. (2015). A comparative analysis of recombinant protein expression in different biofactories: bacteria, insect cells and plant systems. J. Vis. Exp. 97:e52459. doi: $10.3791 / 52459$

Geerlings, M. J., de Jong, E. K., and den Hollander, A. I. (2017). The complement system in age-related macular degeneration: a review of rare genetic variants and implications for personalized treatment. Mol. Immunol. 84, 65-76. doi: 10.1016/j.molimm.2016.11.016

Gitzinger, M., Parsons, J., Reski, R., and Fussenegger, M. (2009). Functional cross-kingdom conservation of mammalian and moss (Physcomitrella patens) transcription, translation and secretion machineries. Plant Biotechnol. J. 7, 73-86. doi: 10.1111/j.1467-7652.2008.00376.x

Goicoechea de Jorge, E., Caesar, J. J. E., Malik, T. H., Patel, M., Colledge, M., Johnson, S., et al. (2013). Dimerization of complement factor H-related proteins modulates complement activation in vivo. Proc. Natl. Acad. Sci. U.S.A. 110, 4685-4690. doi: 10.1073/pnas.1219260110

Häffner, K., Parsons, J., Bohlender, L. L., Hoernstein, S., Niederkrüger, H., Fode, B., et al. (2017). Treatment of experimental C3 Glomerulopathy by human complement factor $\mathrm{H}$ produced in glycosylation-optimized Physcomitrella patens. Mol. Immunol. 89:120. doi: 10.1016/j.molimm.2017.06.050

Halim, A., Westerlind, U., Pett, C., Schorlemer, M., Rüetschi, U., Brinkmalm, G., et al. (2014). Assignment of saccharide identities through analysis of 
oxonium ion fragmentation profiles in LC-MS/MS of glycopeptides. J. Proteome Res. 13, 6024-6032. doi: 10.1021/pr500898r

Harder, M. J., Kuhn, N., Schrezenmeier, H., Höchsmann, B., Von Zabern, I., Weinstock, C., et al. (2017). Incomplete inhibition by eculizumab: mechanistic evidence for residual C5 activity during strong complement activation. Blood 129, 970-980. doi: 10.1182/blood-2016-08-732800

Harris, C. L., Abbott, R. J. M., Smith, R. A., Morgan, B. P., and Lea, S. M. (2005). Molecular dissection of interactions between components of the alternative pathway of complement and decay accelerating factor (CD55). J. Biol. Chem. 280, 2569-2578. doi: 10.1074/jbc.M410179200

Heinen, S., Hartmann, A., Lauer, N., Wiehl, U., Dahse, H. M., Schirmer, S., et al. (2009). Factor H-related protein 1 (CFHR-1) inhibits complement C5 convertase activity and terminal complex formation. Blood 114, 2439-2447. doi: 10.1182/blood-2009-02-205641

Hohe, A., and Reski, R. (2005). Control of growth and differentiation of bioreactor cultures of Physcomitrella by environmental parameters. Liquid culture systems for in vitro plant propagation 81, 307-311.

Hourcade, D. E., Mitchell, L. M., and Oglesby, T. J. (1999). Mutations of the type A domain of complement factor B that promote high-affinity C3b-binding. J. Immunol. 162, 2906-2911.

Huether, C. M., Lienhart, O., Baur, A., Stemmer, C., Gorr, G., Reski, R., et al. (2005). Glyco-engineering of moss lacking plant-specific sugar residues. Plant Biol. 7, 292-299. doi: 10.1055/s-2005-837653

International Federation of Pharmaceutical Manufacturers \& Associations IFPMA (2017). The Pharmaceutical Industry and Global Health - Facts and Figures 2017. Available at: https://www.ifpma.org/wp-content/uploads/2017/02/IFPMAFacts-And-Figures-2017.pdf

Janeway, C. A., and Medzhitov, R. (2002). Innate immune recognition. Annu. Rev. Immunol. 20, 197-216. doi: 10.1146/annurev.immunol.20.083001.084359

Józsi, M., Richter, H., Löschmann, I., Skerka, C., Buck, F., Beisiegel, U., et al. (2005). FHR-4A: a new factor H-related protein is encoded by the human FHR-4 gene. Eur. J. Hum. Genet. 13, 321-329. doi: 10.1038/sj.ejhg.5201324

Józsi, M., and Zipfel, P. F. (2008). Factor H family proteins and human diseases. Trends Immunol. 29, 380-387. doi: 10.1016/j.it.2008.04.008

Kandasamy, M. K., Gilliland, L. U., McKinney, E. C., and Meagher, R. B. (2001). One plant actin isovariant, ACT7, is induced by auxin and required for normal callus formation. Plant Cell 13, 1541-1554. doi: 10.1105/TPC.010026

Kolarich, D., Lepenies, B., and Seeberger, P. H. (2012). Glycomics, glycoproteomics and the immune system. Curr. Opin. Chem. Biol. 16, 214-220. doi: 10.1016/j. cbpa.2011.12.006

Koprivova, A., Stemmer, C., Altmann, F., Hoffmann, A., Kopriva, S., Gorr, G., et al. (2004). Targeted knockouts of Physcomitrella lacking plantspecific immunogenic N-glycans. Plant Biotechnol. J. 2, 517-523. doi: 10.1111/j.1467-7652.2004.00100.x

Kühn, S., Skerka, C., and Zipfel, P. F. (1995). Mapping of the complement regulatory domains in the human factor $\mathrm{H}$-like protein 1 and in factor H. J. Immunol. $155,5663-5670$.

Lang, D., Ullrich, K. K., Murat, F., Fuchs, J., Jenkins, J., Haas, F. B., et al. (2018). The P. patens chromosome-scale assembly reveals moss genome structure and evolution. Plant J. 93, 515-533. doi: 10.1111/tpj.13801

Lomonossoff, G. P., and D’Aoust, M. A. (2016). Plant-produced biopharmaceuticals: a case of technical developments driving clinical deployment. Science 353, 1237-1240. doi: 10.1126/science.aaf6638

Michelfelder, S., Fischer, F., Wäldin, A., Hörle, K. V., Pohl, M., Parsons, J., et al. (2018). The MFHR1 fusion protein is a novel synthetic multitarget complement inhibitor with therapeutic potential. J. Am. Soc. Nephrol. 29, 1141-1153. doi: 10.1681/ASN.2017070738

Michelfelder, S., Parsons, J., Bohlender, L. L., Hoernstein, S. N. W., Niederkrüger, H., Busch, A., et al. (2017). Moss-produced, glycosylation-optimized human factor $\mathrm{H}$ for therapeutic application in complement disorders. J. Am. Soc. Nephrol. 28, 1462-1474. doi: 10.1681/ASN.2015070745

Morgan, B. P., Walters, D., Serna, M., and Bubeck, D. (2016). Terminal complexes of the complement system: new structural insights and their relevance to function. Immunol. Rev. 274, 141-151. doi: 10.1111/imr.12461

Noris, M., and Remuzzi, G. (2015). Glomerular diseases dependent on complement activation, including atypical hemolytic uremic syndrome, membranoproliferative glomerulonephritis, and C3 glomerulopathy: core curriculum 2015. Am. J. Kidney Dis. 66, 359-375. doi: 10.1053/j.ajkd.2015.03.040
Pangburn, M. K., Morrison, D. C., Schreiber, R. D., and Müller-Eberhard, H. J. (1980). Activation of the alternative complement pathway: recognition of surface structures on activators by bound C3b. J. Immunol. 124, 977-982.

Parsons, J., Altmann, F., Arrenberg, C. K., Koprivova, A., Beike, A. K., Stemmer, C., et al. (2012). Moss-based production of asialo-erythropoietin devoid of Lewis A and other plant-typical carbohydrate determinants. Plant Biotechnol. J. 10, 851-861. doi: 10.1111/j.1467-7652.2012.00704.x

Pickering, M. C., Cook, H. T., Warren, J., Bygrave, A. E., Moss, J., Walport, M. J., et al. (2002). Uncontrolled C3 activation causes membranoproliferative glomerulonephritis in mice deficient in complement factor H. Nat. Genet. 31, 424-428. doi: $10.1038 /$ ng912

Rensing, S. A., Lang, D., Zimmer, A. D., Terry, A., Salamov, A., Shapiro, H., et al. (2008). The Physcomitrella genome reveals evolutionary insights into the conquest of land by plants. Science 319, 64-69. doi: 10.1126/science.1150646

Reski, R., Bae, H., and Simonsen, H. T. (2018). Physcomitrella patens, a versatile synthetic biology chassis. Plant Cell Rep. 37, 1409-1417. doi: 10.1007/ s00299-018-2293-6

Reski, R., Parsons, J., and Decker, E. L. (2015). Moss-made pharmaceuticals: from bench to bedside. Plant Biotechnol. J. 13, 1191-1198. doi: 10.1111/pbi.12401

Schaaf, A., Reski, R., and Decker, E. L. (2004). A novel aspartic proteinase is targeted to the secretory pathway and to the vacuole in the moss Physcomitrella patens. Eur. J. Cell Biol. 83, 145-152. doi: 10.1078/0171-9335-00371

Schaaf, A., Tintelnot, S., Baur, A., Reski, R., Gorr, G., and Decker, E. L. (2005). Use of endogenous signal sequences for transient production and efficient secretion by moss (Physcomitrella patens) cells. BMC Biotechnol. 5:30. doi: 10.1186/1472-6750-5-30

Scholz, J., and Suppmann, S. (2017). A new single-step protocol for rapid baculovirus-driven protein production in insect cells. BMC Biotechnol. 17:83. doi: $10.1186 / \mathrm{s} 12896-017-0400-3$

Shi, X., and Jarvis, D. (2007). Protein N-glycosylation in the baculovirus-insect cell system. Curr. Drug Targets 8, 1116-1125. doi: 10.2174/138945007782151360

Skerka, C., Chen, Q., Fremeaux-Bacchi, V., and Roumenina, L. T. (2013). Complement factor $\mathrm{H}$ related proteins (CFHRs). Mol. Immunol. 56, 170-180. doi: 10.1016/j.molimm.2013.06.001

Skerka, C., and Zipfel, P. F. (2008). Complement factor H related proteins in immune diseases. Vaccine 26, I9-I14. doi: 10.1016/j.vaccine.2008.11.021

Stoger, E., Fischer, R., Moloney, M., and Ma, J. K.-C. (2014). Plant molecular pharming for the treatment of chronic and infectious diseases. Annu. Rev. Plant Biol. 65, 743-768. doi: 10.1146/annurev-arplant-050213-035850

Thurman, J. M., and Holers, V. M. (2006). The central role of the alternative complement pathway in human disease. J. Immunol. 176, 1305-1310. doi: 10.4049/jimmunol.176.3.1305

Van Oers, M. M., Pijlman, G. P., and Vlak, J. M. (2015). Thirty years of baculovirus-insect cell protein expression: from dark horse to mainstream technology. J. Gen. Virol. 96, 6-23. doi: 10.1099/vir.0.067108-0

Weise, A., Altmann, F., Rodriguez-Franco, M., Sjoberg, E. R., Bäumer, W., Launhardt, H., et al. (2007). High-level expression of secreted complex glycosylated recombinant human erythropoietin in the Physcomitrella Delta-fuc-t Delta-xyl-t mutant. Plant Biotechnol. J. 5, 389-401. doi: 10.1111/j. 1467-7652.2007.00248.x

Weise, A., Rodriguez-Franco, M., Timm, B., Hermann, M., Link, S., Jost, W., et al. (2006). Use of Physcomitrella patens actin 5' regions for high transgene expression: importance of 5' introns. Appl. Microbiol. Biotechnol. 70, 337-345. doi: $10.1007 / \mathrm{s} 00253-005-0087-6$

Wiedemann, G., van Gessel, N., Köchl, F., Hunn, L., Schulze, K., Maloukh, L., et al. (2018). RecQ helicases function in development, DNA repair, and gene targeting in Physcomitrella patens. Plant Cell 30, 717-736. doi: 10.1105/tpc.17.00632

Wong, E. K., and Kavanagh, D. (2015). Anticomplement C5 therapy with eculizumab for the treatment of paroxysmal nocturnal hemoglobinuria and atypical hemolytic uremic syndrome. Transl. Res. J. Lab. Clin. Med. 165, 306-320. doi: 10.1016/j.trsl.2014.10.010

Yang, Y., Denton, H., Davies, O. R., Smith-Jackson, K., Kerr, H., Herbert, A. P., et al. (2018). An engineered complement factor $H$ construct for treatment of C3 glomerulopathy. J. Am. Soc. Nephrol. 29, 1649-1661. doi: 10.1681/ ASN.2017091006

Zimmer, A. D., Lang, D., Buchta, K., Rombauts, S., Nishiyama, T., Hasebe, M., et al. (2013). Reannotation and extended community resources for the genome of the non-seed plant Physcomitrella patens provide insights into the evolution 
of plant gene structures and functions. BMC Genomics 14:498. doi: 10.1186/1471-2164-14-498

Zimran, A., Brill-Almon, E., Chertkoff, R., Petakov, M., Blanco-Favela, F., Munoz, E. T., et al. (2011). Pivotal trial with plant cell-expressed recombinant glucocerebrosidase, taliglucerase alfa, a novel enzyme replacement therapy for Gaucher disease. Blood 118, 5767-5773. doi: 10.1182/ blood-2011-07-366955

Zipfel, P. F., Jokiranta, T. S., Hellwage, J., Koistinen, V., and Meri, S. (1999). The factor $\mathrm{H}$ protein family. Immunopharmacology 42, 53-60. doi: 10.1016/ S0162-3109(99)00015-6

Zipfel, P. F., and Skerka, C. (2009). Complement regulators and inhibitory proteins. Nat. Rev. Immunol. 9, 729-740. doi: 10.1038/nri2620
Conflict of Interest Statement: The authors are inventors of patents and patent applications related to the production of recombinant proteins in P. patens. RR is an inventor of the moss bioreactor and a founder of Greenovation Biotech. He currently serves as advisory board member of this company.

Copyright (C) 2019 Top, Parsons, Bohlender, Michelfelder, Kopp, Busch-Steenberg, Hoernstein, Zipfel, Häfner, Reski and Decker. This is an open-access article distributed under the terms of the Creative Commons Attribution License (CC BY). The use, distribution or reproduction in other forums is permitted, provided the original author(s) and the copyright owner(s) are credited and that the original publication in this journal is cited, in accordance with accepted academic practice. No use, distribution or reproduction is permitted which does not comply with these terms. 